\title{
Determination of the Transit Fee for Mongla-Ghasiakhali Canal: Savings from the Daily Running Cost of Ships
}

\author{
Khandaker Rasel Hasan ${ }^{1}$, Md. Mashiur Rahaman ${ }^{2}$ and Nastia Degiuli ${ }^{2}$ \\ 1. Department of Port and Shipping Management, Bangabandhu Sheikh MujiburRahman Maritime University, Dhaka 1000, \\ Bangladesh \\ 2. Faculty of Mechanical Engineering and Naval Architecture, University of Zagreb, Zagreb 10000, Croatia
}

\begin{abstract}
MG (Mongla-Ghasiakhali) Canal, a man-made canal that connects the southwestern part of Bangladesh, is one of the industrial zones where the second largest seaport, the Mongla seaport, and two inland river ports are situated. The Government of Bangladesh maintained the canal since it was opening in 1973. From 2010, the maintenance excavation of the canal was postponed because the rate of siltation was higher than the excavation works allocated for it. Paucity of budget was the main reason as the return from the canal was too low to recover the minimum part of the budget. The objective of the present study is to determine the minimum tool rate based on the savings by the vessels operator who will use the canal. At present, almost all types of goods are transported through the waterway canal inside the largest single block of the tidal halophytic mangrove forest in the world, Sundarban (a United Nations heritage) and that causes serious environmental problems and threats to the biodiversity of the forest. Therefore, utilization of the MG Canal will not only be an alternative waterway network for transporting of goods but also reduce the voyage length. To determine the minimum toll rate, several government agencies of Bangladesh and operators have been contacted to collect the data both quantitatively and qualitatively. Real-time data has been used for calculating the minimum standard tool rate.
\end{abstract}

Key words: Transit fee, Mongla-Ghasiakhali Canal, mangrove forest, toll rate, inland waterways.

\section{Introduction}

MG (Mongla-Ghasiakhali) Canal is an important waterway that connects the Mongla seaport and Khulna and Nowapara river ports to the rest of Bangladesh. Moreover, this waterway is also a classified route under the Protocol on IWT (inland water transit) and trade, serving the inter country trade and transit between Bangladesh and India. MG Canal is a man-made canal reducing the length of natural waterways inaugurated in 1973 and become critical to maintain since the upstream water flow in this region has been reducing drastically since 1990s. Expensive dredging works failed to keep it navigable since 2010, as it was found that the siltation rate in this area is much higher than the rate of excavation. The cost of dredging

Corresponding author: Md. Mashiur Rahaman, assistant professor, research fields: computational fluid dynamics, marine transportation, dredging and ship recycling. E-mail: mashiurrahaman@name.buet.ac.bd. is typically funded by the Government of Bangladesh while the revenue collected from the canal, as a toll is minimal compared to the dredging cost. At present, vessels pass through the largest mangroves forest of the world called Sundarban, which is a UNESCO (United Nation Educational, Scientific and Cultural Organization) world heritage. In order to restore the navigability and make the MG Canal sustainable, a huge capital investment is required for increasing the volume of capital dredging, tidal river management system, continuous large amount of maintenance dredging, as well as construction of a navigational lock at least at one end of the canal. However, the return of this huge investment is low as the government agency, BIWTA (Bangladesh Inland Water Transport Authority) collects a minimal amount of toll per tonnage. Therefore, a cost sharing mechanism has to be developed materializing the factors that would atract the operators to use the canal rather than the natural 
route through the world heritage.

\section{Literature Review}

Huebner [1] identified five primary routine factors that influence the operators to use Panama Canal including the distance or length of the voyage, the time to reach the distance, the fuel cost, relative ease of profitable cargo and the transshipment cost. Heitmann et al. [2] in determining the transit charge for the Kiel Canal in Germany identified the savings from the total cost of a ship travelling from one port to another using the alternative routes where also the distance and time factor have become the main influence. The essence of using the MG Canal is obviously influenced by the distance, time, as well as the avoidance of Sundarban. In determining the savings for a vessel, here the cost of running a ship via alternative routes is analyzed. Cost of running a ship can be divided into five components, such as capital cost, operating cost, voyage cost, periodic maintenance cost and cargo handling cost according to Heitmann et al. [2] and Stopford [3]. In determining the transit charge for MG Canal, considerations of only first three components is good enough as the vessels crossing the canal or not have to go with periodic maintenance and the same port dues, as they are calling the same domestic ports under the same operating agency. It would be easy to calculate the operating savings for a vessel using the canal or not if the daily cost of running that particular vessel could be identified. An alternative measurement can be taken if the carrying cost per tonnage per $\mathrm{km}$ is considered and it would rather be easy as the carrying cost per ton per kilometer for inland water transport is already being determined by a study conducted by WB (World Bank) [4], which is less than Takal.00 per ton per kilometer or USD0.0125 per ton per kilometer. However, here the cost of vessels waiting at different ports might not be taken into consideration, which is, therefore, not representing the actual capital cost of the vessel. Therefore, daily cost identification would provide a much better reflection of the cost of running a vessel where all the components are covered. The daily cost of running a vessel in present study is the summation of daily capital cost, daily operating cost and the daily voyage cost. Pucuca [5] classified these components as two major items, which are the daily fixed cost and the daily voyage cost. The daily fixed cost includes daily operating cost and the daily depreciation cost of the vessel as the capital cost. The capital cost of the vessel can also alternatively be identified from the chartering rate of the vessel if it is not owned by the operator and is rather operated under a voyage, time or bare-board charter party [2].

\section{Inland Waterways Core Network of Bangladesh}

It is important to provide an idea of the inland waterways of Bangladesh so that the economic importance of MG Canal can be understood. Fig. 1 shows the inland waterways core network of Bangladesh with the location of MG Canal. It is seen from Fig. 1 that the inland waterways core networks start from the Indian border of Bangladesh at Raimongal through Chalna, Khulna, Mongla, Kaukhali, Barisal, Hizla, Chandpur to Narayangonj and Dhaka area. The waterway is further spread divided into two parts: One goes through Aricha, Sirajganj, Bahadurabad upto the Indian border at Chilmari and the other goes through Bhairab Bazar, Ashuganjupto Sylhet region and further towards the Indian border at Chatak and Zakiganj. Moreover, the downstream of Chandpur is the waterway that connects the Chittagong Port to other parts of the country. The MG Canal is located between Mongla seaport in Khulna and Kaukhali. The waterway from Khulna to Kaukhali through MG Canal length is $128 \mathrm{~km}$ while the length increases to $179 \mathrm{~km}$ through the natural one called the Joymonirgul-bogi area through the Sundarban. Therefore, the use of MG Canal will not only reduce $50-\mathrm{km}$ length of the waterway but also avoid the voyage through Sundarban. 


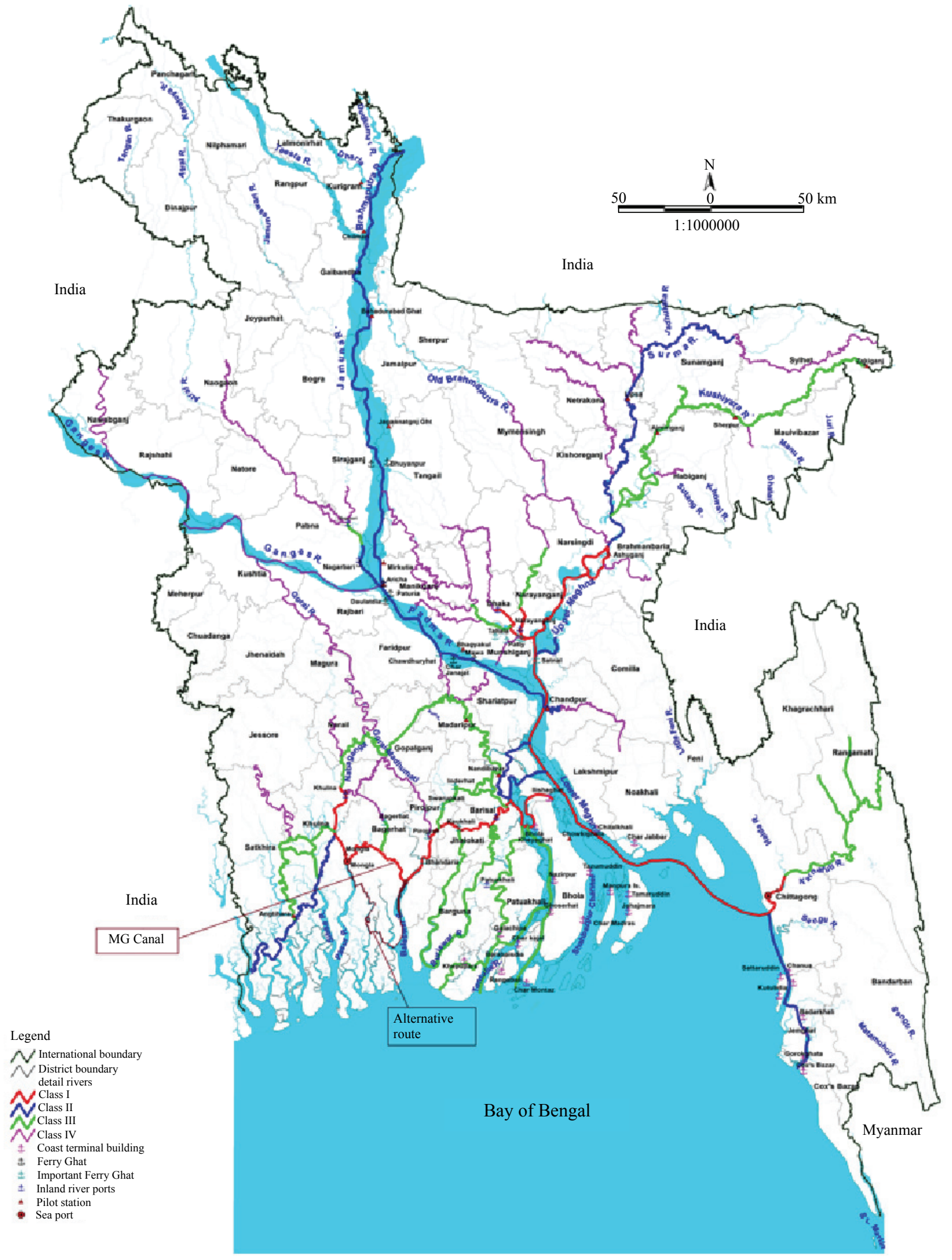

Fig. 1 Inland core waterways network of Bangladesh.

Source: IWT Master Plan, BIWTA. 


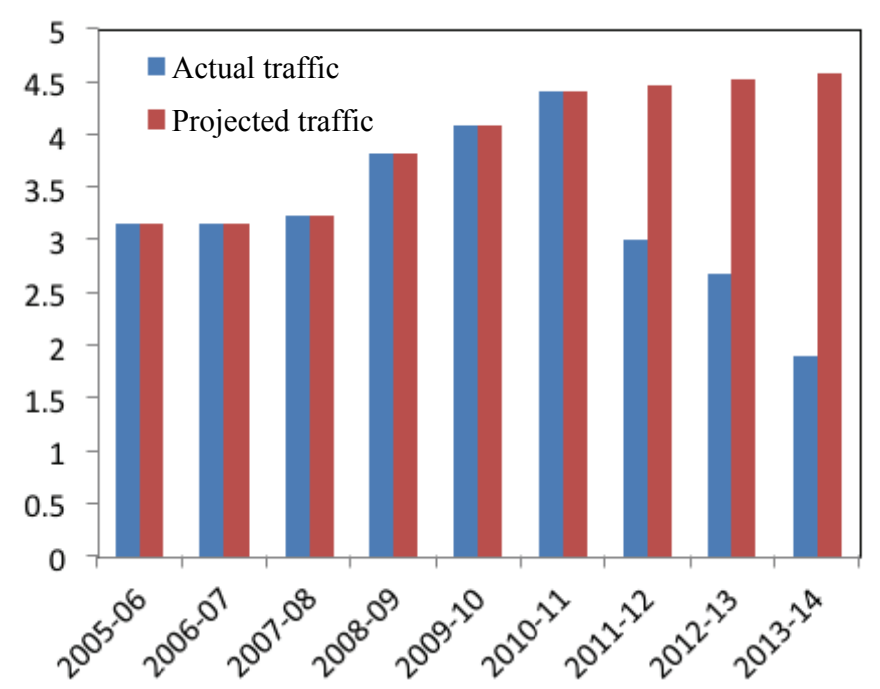

Fig. 2 Actual and projected tonnage passes through the canal in million tons.

\section{The Traffic through MG Canal}

The traffic figure is the biggest limitation in this study. Organized information of the traffic passing through the canal daily is really tough to determine. BIWTA used to lease out the canal to private operators who are only responsible to collect the toll. The toll is determined on the tonnage carried out by a particular vessel. As a result, the BIWTA accounts show a monetary amount deposited by the lessee. The present research simply divided that monetary figure by the per tonnage toll rate set out by BIWTA for every tonnage of cargo passing through the canal. The graph shows the actual and projected amount of cargo in million tons transported through the canal in the year from 2005-06 to 2013-14. In Fig. 2, it can be seen that the actual figure of the tonnage transited through the canal shows a sharp decline for the year of 2011 2012, which is because the draft limitations in the canal have become significant over time. If the navigability of the canal was smooth, the traffic figure might have risen to around 5,000,000 $t$ in the year of 2013 2014 following the simple growth rate of the previous years. Fig. 2 gives the idea of the importance, as well as the potentiality of the MG Canal in terms of volume of cargo transited through it.

However, to understand the significance in terms of domestic and international trade, a more detailed analysis has been done in present study. The traffic between the two ends of the canal can be classified into three categories. The first category is the domestic cargo movement that is the cargo from Khulna and Nowapara river ports to other parts of the country, and vice-versa. The cargo-handling figure of Khulna and Nowapara river ports could provide a picture of the importance of MG Canal. The port at Nowapara handles substantial amount of fertilizer and food grains along with huge amount of construction materials, like sand and stones. Most of the materials handled in Nowapara are transported from the other end of the canal while the fertilizer which is mostly comes from the Mongla seaport. On the other hand, the traffic handled at Khulna river port is basically fertilizer, such as clinker, fly ash and petroleum including construction materials like as Nowapara. The commodities include fertilizer-clinkers mostly handled from the Mongla seaport and fly ash from India. Therefore, those cargoes do not need to pass through the canal, while the construction materials and food grains. The total sea borne trade for food grains, fertilizer and clinker the percentage of market share of Chittagong and Mongla seaports is 98:2, 74:26 and 93:7 according to the ADB (Asian Development Bank) [6]. Therefore, a substantial amount of food 
grains handled in Chittagong seaport using the inland waterways goes to Khulna and Nowpara regions. Moreover, a substantial amount of fuel oil is handled at Khulna river port, which basically comes through the Chittagong seaport and hence needs to pass the canal to come to Khulna. According to BIWTA statistics, around 2,000,000 $\mathrm{t}$ of cargo is handled in Khulna and Nowapara and over 2,000 vessels call to these ports yearly. In the trade route, most of the demand for IWT is one way [4] and the vessels calling to Khulna and Nowapara might come back empty from the other end of the canal thereby doubling the number of vessels crossing the canal. The second category is the import-export cargo uses the Mongla seaport destined to Dhaka, Narayanganj and other part of the country and from those parts back to Mongla. There is no railway connectivity to Mongla seaport and the lack of bridge on the river Padma enforce the shippers to rely on the inland waterways, which is cost-effective. Container transportation through IWT has not yet started, and, therefore, no containers are being transported from Mongla port to the rest of the country through IWT. The bulk-commodity handling figure of the Mongla seaport is provided in the Table 1 [7]. It is observed that, in 2013 2014, a total of 3,500,000 $t$ of bulk cargo has been handled at Mongla seaport. As Dhaka and Narayanganj are the main hinterland of the cargo, a substantial amount of these cargoes could pass through the MG Canal.

The third category is the inter country trade and transit cargo which is using this waterways since 1973 following the signing of the protocol between India and Bangladesh. As the trade between these two countries is increasing sharply, MG Canal has become extremely important to the shippers of both countries. From Table 2, it can be seen that a substantial number of vessels as well as tons of cargo pass through the canal under the said protocol [8]. Interestingly, the vessels operated under this protocol are used to transport only one commodity that is fly ash, which is used in cement factories. And these vessels cross the canal twice; to go to India empty and then come back to Bangladesh with the fly ash. Hence the number of vessels crossing the canal in this case would be doubled.

\section{Methodology}

The traffic pattern in the previous section was analyzed to understand the amount and types of the cargo and the number and types of the vessels. In order to determine the savings of the running cost of a ship, the standard sizes in each and every category of the vessels using the trade route should be identified and for this purpose, the traffic pattern is examined here.

From the statistical review above, a substantial amount and a substantial variety of cargo, as well as vessels, are supposed to transit through this canal. Moreover, it is not easy to determine a standard toll rate for the canal as different commodities on different sizes of vessels are crossing the canal. On the contrary, the transportation rates per tonnage of commodity for domestic trade is quite different from the Bangladesh-India inter cargo trade and transit market. The inter country trade is dominated by only one commodity while the domestic trade commodities vary.

However, the only available standard data is the inter country trade and transit data, since in each and every voyage, the operator needs to take a permission from the designated authority BIWTA and thus BIWTA has

Table 1 Annual cargo handling statistics of Mongla seaport.

\begin{tabular}{llll}
\hline Year & Import $(\mathrm{t})$ & Export $(\mathrm{t})$ & Total $(\mathrm{t})$ \\
\hline $2009 \sim 2010$ & $1,502,050$ & 147,233 & $1,649,283$ \\
$2010 \sim 2011$ & $2,529,853$ & 166,418 & $2,696,271$ \\
$2011 \sim 2012$ & $2,482,432$ & 137,465 & $2,619,897$ \\
$2012 \sim 2013$ & $2,946,222$ & 201,352 & $3,147,574$ \\
$2013 \sim 2014$ & $3,402,402$ & 141,547 & $3,543,949$ \\
\hline
\end{tabular}

Source: Mongla Port Authority website. 
Table 2 Commodity-wise annual inter country trade and transit statistics

\begin{tabular}{llcll}
\hline Year & Inter-country trade $(\mathrm{t})$ & Transit (numbers) & Total $(\mathrm{t})$ & Vessels (nos.) \\
\hline $2009 \sim 2010$ & $1,278,636$ & 5,765 & $1,284,401$ & 1,934 \\
$2010 \sim 2011$ & $1,429,633$ & 7,298 & $1,436,931$ & 2,084 \\
$2011 \sim 2012$ & $1,479,612$ & 2,695 & $1,482,307$ & 2,069 \\
$2012 \sim 2013$ & $1,535,334$ & 18,685 & $1,554,019$ & 2,009 \\
$2013 \sim 2014$ & $1,931,576$ & 2,373 & $1,933,949$ & 2,363 \\
\hline
\end{tabular}

Source: BIWTA

Table 3 Classified data for one month under the Bangladesh-India protocol.

\begin{tabular}{lllll}
\hline $\begin{array}{l}\text { Classes based on } \\
\text { capacity }(\mathrm{t})\end{array}$ & $\begin{array}{l}\text { Frequency/number of } \\
\text { vessels (numbers) }\end{array}$ & $\begin{array}{l}\text { Average size for each } \\
\text { classes }\end{array}$ & $\begin{array}{l}\text { Total tonnage capacity } \\
\text { for class }\end{array}$ & Average vessel size (t) \\
\hline Class $408-632$ & 28 & 520 & 14,560 & \\
Class $633-857$ & 90 & 745 & 67,050 & 878 \\
Class $858-1082$ & 50 & 970 & 48,500 & \\
Class $1083-1307$ & 26 & 1,195 & 31,070 & 19,880 \\
Class $1308-1532$ & 14 & 1,420 & 3,289 & \\
Class $1532-1757$ & 2 & $1,644.5$ & & \\
\hline
\end{tabular}

the record of it. The data from the BIWTA have been used here to analyze the size of the vessel. Real-time data of one-month duration, i.e., April 2015, have been analyzed for determining the vessels dimension that is shown in Table 3. The data were found as raw data, which has been tabulated first forming several classes based on the carrying capacity of tones. A number of total 210 vessels took the permission from the Authority to cross the border for importing cargoes of which only three vessels took the permission to carry goods other than fly ash. Among these 210 vessels, the lowest capacity vessel has a carrying capacity of $408 \mathrm{t}$ while the largest one has a carrying capacity of 1,755 t.

From Table 3, the average vessel size is found having a tonnage capacity of $878 \mathrm{t}$. In our cost of running the ship via alternative route, vessels near to this size would be used as standard vessel size.

From Heitmann et al. [2], the daily cost of running a ship is:

$$
\begin{gathered}
C_{d}=O_{d}+D_{d}+F_{d} \\
=\left(M_{d}+S_{d}+(R \& M)_{d}+I_{d}+A_{d}\right)+D_{d}+F_{d}
\end{gathered}
$$

where:

$C_{d}$ : cost of running ship daily;

$D_{d}$ : daily depreciation of a certain vessel;

$M_{d}$ : daily manning cost;
$S_{d}$ : daily store cost;

$(R \& M)_{d}$ : daily repair and maintenance cost;

$I_{d}$ : daily insurance cost;

$A_{d}$ : daily administrative cost;

$F_{d}$ : daily fuel cost.

In order to determine the cost components for a particular size of a vessel, the authors communicated with a well-established operator who operates vessels both in the domestic and India-Bangladesh protocol route. It operates not only its own vessels but also chartering vessels specifically under voyage charter. In present study, the authors considered the vessels owned by this particular operator, which is also constructed by his own capital rather taking any sorts of capital loan. Therefore, it has eased the calculation of daily capital expenditure that is only the depreciation rather consideration of any interest. The different cost component in the light of a round voyage under the India-Bangladesh protocol, which takes on average 35 days, where on average the vessel needs 15 days to load and unload the cargo and having several security checks and custom procedures and 20 days in come and forth voyage is being mentioned in Table 4 .

Analyzing the cost components in the Table 4, it is calculated that, for a round trip from Narayanganj to 
Table 4 Calculation of daily running cost of ship.

\begin{tabular}{|c|c|c|c|c|}
\hline \multicolumn{3}{|c|}{$\begin{array}{l}\text { Tonnage carrying capacity of the vessel and the corresponding costs in Taka } \\
\text { (USD, considering USD1 = Taka80) }\end{array}$} & \multicolumn{2}{|c|}{$\begin{array}{l}\text { According to carrying capacity } \\
\text { daily cost }\end{array}$} \\
\hline Different cost components & $750 t$ & $900 \mathrm{t}$ & - & - \\
\hline Construction cost & $20,000,000(250,000)$ & $25,000,000(312,500)$ & - & - \\
\hline $\begin{array}{l}\text { Depreciation cost considering an } \\
\text { economic life of } 20 \text { years }\end{array}$ & $1,000,000(12,500) /$ annual & $1,250,000(15,625) /$ annual & USD35 & USD43 \\
\hline Manning cost including store & $90,000(1,125) /$ month & $135,000(1,687.5) /$ month & USD37.5 & USD56.5 \\
\hline Repair and maintenance (regular) & $250,000(3,125) /$ year & $300,000(3,750) /$ year & USD8.5 & USD10.5 \\
\hline Insurance cost & Nil & Nil & - & - \\
\hline Administrative cost & $100,000(1,250) /$ month & $100,000(1,250) /$ month & USD41.5 & USD41.5 \\
\hline Fuel & $250,000(3,125) /$ voyage & $300,000(3,750) /$ voyage & USD156.5 & USD187.5 \\
\hline Total & - & - & $\begin{array}{l}\text { USD279 } \\
\text { (in Taka 22,320) }\end{array}$ & $\begin{array}{l}\text { USD339 } \\
\text { (in Taka 27,120) }\end{array}$ \\
\hline
\end{tabular}

Kolkata for a 750-t carrying capacity vessel, the daily cost of running is USD279 where for a 900-t carrying capacity vessel it is USD339. It is found that a vessel passing through the Sundarban rather the MG Canal needs around $10 \mathrm{~h}$ more. Moreover, the vessels cannot ply through the Sundarban during night. Therefore, a canal's whole day savings can be considered for a vessel plying through the MG Canal justifying a range of around USD200 USD 400 toll per vessel, whereas under the present tool rate the total toll for those vessels stands USD37.5 and USD45 (per tonnage toll rate is Taka 4 or USD0.05 now). It is to be noted the duration of voyage, which is 35 days all together where around 15 days the vessel needs to wait at different stations for different measures. Therefore, if those unwanted delays could be reduced the justification of toll rate becomes stronger and in case of the domestic movement there is no such kind of delays.

\section{Further Study}

It is observed that, under the limited scope of this paper, it was not straight forward to determine a standard toll rate for the vessels plying through the canal since there are two distinct trade pattern, the domestic and the India-Bangladesh trade. Moreover, the commodity could be classified, as the bulk high value goods, for example, the food grains, fertilizer, cement, clinkers and petroleum, etc., the bulk low value goods, like sand, stone etc. Moreover, a more or less equal number of empty vessels would move through the canal. Therefore, a tool pattern considering all these categories needs to determine. However, the analysis done in this paper might able to create an impression that the re-excavation, as well as maintenance of the canal, is possible with the toll collected from the canal. In addition to the above, the introduction of container transportation through waterways would enhance the traffic sharply, which might create more value to the canal operation.

\section{Conclusions}

The MG (Mongla-Ghasiakhali) Canal is the lifeline for the economy of the southwestern region of Bangladesh. Even though it's economic importance permits its operation, but the canal can not be run on its own. The vessel operators can contribute from their savings to keep the canal alive, which intern would benefit both the public and private sector. And to do so, the Government of Bangladesh has to initiate detailed cost benefit analysis or the canal could be run on a public-private partnership basis that might enhance efficiency for the long life of the canal, as well as the inland water connectivity of the southwestern region with the rest of the region of Bangladesh. Moreover, uses of the MG Canal will also reduce the environmental impacts on the biodiversity of the Sundarban. 


\section{Acknowledgments}

This research was supported by Experts4Asia, EU↔Asia Mobility Project Scholarship for Study, Research and Training in EU and Asia Program through the Erasmus.

\section{References}

[1] Huebner, G. G. 1915. "Economic Aspect of the Panama Canal." The American Economic Review 5 (4): 816-29. Accessed July 21, 2015. http://www.jstor.org/stable/ 1809632.

[2] Heitmann, N., Rehdanz, K., and Schmidt, U. 2011. "Determining Optimal Transit Charges: The Kiel Canal in Germany." Kiel Institute for the World Economy. Accessed July 21, 2015. https://www.ifw-members.ifwkiel.de/publications/determining-optimal-transit-charges-t he-kiel-canal-in-germany/kwp-1741.pdf.

[3] Stopford, M. 2007. Maritime Economics. 2nd ed. New York: Routledge.

[4] WB (World Bank). 2007. "Peoples' Republic of Bangladesh, Revival of Inland Water Transport: Options and Strategies." WB. Accessed August 2, 2015. http://siteresources.worldbank.org/INTBANGLADESH/ Resources/BDS20.pdf.

[5] Pocuca, N. 2006. "Methodology of Day-to-Day Ship Costs Assessment." Transportation Economic Review: Traffic \& Transportation 18 (5): 337-45. Accessed August 25, 2015. http://www.fpz.unizg.hr/traffic/index. php/PROMTT/article/download/704/558.

[6] ADB (Asian Development Bank). 2011. Technical Assistance Consultant's Report Bangladesh: Port and Logistics Efficiency Improvement (Project Number: 39460). ADB report. Accessed September 5, 2015. http://www.adb.org/sites/default/files/project-document/81 001/39460-012-tacr-01.pdf.

[7] Mongla Port Authority. 2015. "Bulk-Commodity Handling Figure of the Mongla Seaport." Mongla Port Authority. Accessed September 23, 2015. http://www.mpa.gov.bd.

[8] BIWTA (Bangladesh Inland Water Transport Authority). 2015. "A Substantial Number of Vessels as Well Tons of Cargo Pass through the Canal under the Protocol between India and Bangladesh." BIWTA. Accessed October 8, 2015. http://www.biwta.gov.bd. 